\title{
Host-plant quality adaptively affects the diapause threshold: evidence from leaf beetles in willow plantations
}

\section{Peter Dalin and Sören Nylin}

Peter Dalin (Peter.Dalin@slu.se) Swedish University of Agricultural Sciences, Department of Ecology, P.O. Box 7044, SE-750 07 Uppsala, Sweden. Fax: +46-18-672383.

Sören Nylin (Soren.Nylin@zoologi.su.se) Department of Zoology, Stockholm University, SE10691 Stockholm, Sweden. Fax: +46-8-167715. 


\section{Abstract}

2 Voltinism (the number of generations produced per year) of herbivorous insects can vary

3 depending on environmental conditions. The leaf beetle Phratora vulgatissima is commonly

4 univoltine in central Sweden but will sometimes initiate a second generation on coppiced

5 willows (Salix viminalis) grown in plantations for bioenergy purposes. The study investigated

6 whether increased voltinism by P. vulgatissima can be explained by (1) rapid life-cycle

7 development in plantations allowing two generations, or (2) postponed diapause induction on

8 willows grown in plantations. In the field, no difference was found in the phenology or

9 development of first-generation broods between plantations (S. viminalis) and natural willow

10 habitats (S. cinerea). On re-sprouting shoots of recently coppiced S. viminalis, however, the

11 induction of diapause occurred 1-2 weeks later than on mature (un-coppiced) plants. A

12 laboratory experiment indicated no genetic difference in the critical day-length for diapause

13 induction (CDL) between beetles from plantations and natural habitats. Although development

14 time was unaffected by host-plant quality, CDL was prolonged by almost an hour when the

15 beetles were reared on a sub-optimal willow species (S. phylicifolia). A subsequent experiment

16 found that diapause incidence, when the beetles were reared on new leaves from re-sprouting

17 shoots of previously coppiced $S$. viminalis and $S$. cinerea plants, was significantly less than when

18 the beetles were reared on mature leaves from un-coppiced plants. The study suggests that $P$.

19 vulgatissima has a plastic diapause threshold influenced by host-plant quality. The use of host-

20 plant quality as a diapause-inducing stimulus is likely to be adaptive in cases where food

21 resources are unpredictable, such as when new host-plant tissue is produced after a disturbance.

22 Coppiced willows may allow two beetle generations because re-sprouting willows continue to

23 produce new leaves throughout the season. 


\section{Introduction}

26 The number of generations that insects produce per year (i.e. voltinism) is an important life-

27 history trait that can strongly affect population growth, fitness and potential rate of adaptability

28 (Kurota and Shimada 2002, Steinbauer et al. 2004, Yamanaka et al. 2008). Voltinism in

29 herbivorous insects often varies across latitude and altitude (Tauber et al. 1986, Masaki 1999).

30 Insects with a wide distribution range may therefore produce one generation per year (univoltine

31 life-cycle) at northern latitudes where the growing season is relatively short, but produce two

32 (bivoltine) or even more (multivoltine) generations further south. Such latitudinal clines in

33 voltinism partly reflect local adaptations to seasonal environments, with a genetic basis, but

34 plasticity in life-history traits is also a crucial component of the insects' seasonal adaptations

35 (Nylin and Gotthard 1998). Plasticity in voltinism may allow the insect to immediately adjust the

36 number of generations in response to prevailing environmental conditions, without need for

37 selection to operate, and there is indeed evidence that recent climate change has led to extra

38 generations in response to warmer temperature conditions, through plasticity (Altermatt 2010,

39 Poyry et al. 2011). For most insects, however, we have too limited knowledge about what

40 processes influence such life-history plasticity to be able to predict under what circumstances

41 voltinism may change.

43 In temperate climate zones, insect voltinism is determined by the number of generations

44 produced before the seasonal timing of winter diapause (Tauber et al. 1986, Danks, 2007).

45 Diapause is a dormant stage characterized by lowered metabolic rates, cold hardening and

46 cessation of reproductive development in insects that overwinters as adults (Kostal 2006). Many

47 insects have a facultative diapause, i.e. individuals make a "decision" during development to 
48 either enter diapause (thus, to wait with reproduction until the following year) or to exhibit direct

49 development and to become reproductively active as adults and produce another generation

50 within the same year (Gotthard 2008). This decision-making is determined by seasonal cues to

51 which the insects respond for the induction of diapause, with day-length (photoperiod) being the

52 most important cue (Nelson et al. 2010, Saunders 2010). Hence, in insects with facultative

53 diapause voltinism is in a sense always a plastic trait, responding primarily to day-length. On the

54 other hand, the critical day-length (CDL), defined as the day-length when $50 \%$ of a population

55 enters diapause (Tauber et al. 1986, Saunders 2010) is a genetically determined property that

56 varies adaptively among insect populations (Bradshaw 1976, Solbreck and Sillen-Tullberg 1981;

57 Masaki 1999, Dalin et al. 2010). This critical day-length sets the timing for when diapause

58 induction occurs over the course of the year and can therefore severely limit the possibilities for

59 altered voltinism (Tobin et al. 2008).

60

61 Importantly, however, other factors that - in contrast to day-length - can vary from year to year

62 as well as seasonally, such as temperature and (in the case of herbivorous insects) host-plant

63 quality, may also plastically affect the incidence of diapause and hence voltinism (Tauber et al.

64 1986). These effects can be indirect or direct, and it is seldom clear whether they are adaptations

65 per se, i.e. have been selected for rather than just having incidental positive effects on fitness

66 (Gotthard and Nylin 1995). Both temperature and host-plant conditions can strongly influence

67 growth and development during the season and will in the field therefore indirectly influence

68 voltinism by affecting the timing of when the insect reaches the critical stage for diapause

69 induction. For example, slow growth on a poor host-plant or in response to low temperature

70 conditions will delay the critical stage for diapause induction. If the critical stage is reached after 
71 day-length has declined below CDL; the insect will choose the developmental pathway leading

72 to diapause. Furthermore, laboratory studies suggest that temperature and host-plant quality can

73 modify the insects' photoperiodic responses (Masaki 1999, Ishihara and Ohgushi 2006, Dolezal

74 and Sehnal 2007, Dalin et al. 2010), and such more direct effects on voltinism are stronger

75 candidates for being true adaptations to environmental variation (in the sense of Gotthard and

76 Nylin 1995). Since temperature - for physical and chemical reasons - affects so many processes

77 in the insect, it may be almost impossible to disentangle adaptive responses to temperature from

78 spurious indirect effects, but effects of host plant quality provides an interesting opportunity for a

79 deeper understanding of voltinism plasticity.

81 For example, Hunter and McNeil (1997) showed that the generalist lepidopteran Choristoneura

82 rosaceana (Lepidoptera: Tortricidae) was more likely to enter diapause when reared on a poor

83 quality food than when reared on high-quality food under controlled laboratory conditions, and

84 similar results were found in the polyphagous comma butterfly Polygonia c-album (Wedell et al.

85 1997). These studies suggest that food quality can influence the induction of diapause and

86 voltinism of herbivorous insects, and such a plastic diapause threshold could prevent the insects

87 from producing maladaptive generations on host-plants of low or declining quality. A poor host-

88 plant may indicate that the plant cannot support rapid-enough growth and development for

89 another generation to develop within the same year and, thus, that it is better to wait with

90 reproduction until the following year. Even in these laboratory experiments, however, it is still

91 not clear whether the insects can use the chemical properties of the host-plant as a direct signal

92 or cue - similar to photoperiod - influencing the induction of diapause, or whether the

93 potentially adaptive response is rather to growth rate, as determined by host quality, or indeed 
94 even simply constitutes a spurious physiological side-effect of the host plant (Wedell et al.

95 1997).

96

97 The leaf beetle Phratora vulgatissima is an important pest in willow plantations grown for

98 bioenergy in northern Europe (Sage and Tucker 1998, Björkman et al. 2000, Dalin et al. 2009). It

99 is commonly univoltine in northern Europe and bivoltine in central Europe. The species

100 sometimes initiate a partial second generation also in northern Europe (Dalin 2011). This has

101 particularly been observed in short-rotation coppiced willow (Salix viminalis) plantations grown

102 for biomass productions in Sweden (P. Dalin, pers. obs.). The leaf beetle overwinters in the adult

103 stage and emerges from overwintering sites in the spring. The phenology of adult emergence is

104 usually well synchronized with willow bud-break in the spring. Adults feed on newly developed

105 leaves and oviposit on the ventral side of the leaves. Larvae of the first generation continue to

106 feed on leaves during the summer before they pupate in the soil. The next generation of adult

107 beetles (first-generation adults) emerges in late July or beginning of August in central Sweden

108 (Dalin 2011). These adults are normally in reproductive diapause and become the overwintering

109 generation. However, those individuals that complete development to adulthood before August

110 may become reproductively active and initiate a second generation (Dalin 2011).

112 The purpose of this study was to investigate whether the partial second generation of $P$.

113 vulgatissima in willow plantations could be explained by (1.) advanced phenology and

114 accelerated development of first-generation broods in willow plantations, or (2) postponed

115 diapause induction of beetles in willow plantations. The central Swedish population that we

116 study has previously been shown to have a facultative diapause induced by day-length with a 
117 CDL estimated to be 18 hours 10 minutes (Dalin 2011). A second purpose of our study was to

118 investigate whether CDL may differ between $P$. vulgatissima populations from willow

119 plantations (S. viminalis) and natural willow stands (S. cinerea). This was tested by rearing the

120 insects under controlled conditions in the laboratory. A genetic difference in CDL between host-

121 populations, with an expected shorter CDL in beetles from plantations, could explain why the

122 species is more likely to produce a second generation in plantations. We also tested the

123 hypothesis that $P$. vulgatissima has a plastic diapause threshold that is influenced by host-plant

124 quality. First, we predicted CDL to be prolonged when the species was reared on a sub-optimal

125 willow; in this case S. phylicifolia that contains relatively high concentrations of phenolic

126 glycosides. Second, if the beetles are able to postpone diapause in response to vigorous host-

127 plant growth on previously coppiced willows, we predicted diapause incidence to be reduced if

128 the species was reared on newly produced leaves from coppiced willows (S. viminalis and $S$.

129 cinerea) than when reared on older leaves from mature and un-coppiced plants.

\section{Materials and Methods}

132 Life-cycle development and diapause induction of field populations

133 During the summer 2009, we studied when natural populations of $P$. vulgatissima enter diapause

134 in the field on S. viminalis in plantations and on S. cinerea in natural willow habitats. A

135 postponed diapause induction in plantations could explain why the species is more likely to

136 initiate a second generation in this habitat. In the following year (2010), we studied the

137 phenology and life-cycle development of first-generation broods of naturally occurring

138 populations of $P$. vulgatissima in one willow plantation and one natural willow habitat in the

139 field. If the beetles are able to complete development of the first generation faster in willow 
140 plantations, this could explain why $P$. vulgatissima is more prone to produce a second generation

141 in this habitat.

143 From mid-July in 2009 (Julian date: 196), when the first-generation adults started to emerge in

144 the field, we collected adult beetles once every week to estimate the proportion of females in 145 diapause over time. The study was done at two willow plantations (S. viminalis) and two natural 146 willow habitats (S. cinerea) located within $20 \mathrm{~km}$ from the Ultuna campus of the Swedish 147 University of Agricultural Sciences in Uppsala (5949’ $\left.\mathrm{N}, 17^{\circ} 40^{\prime} \mathrm{E}\right)$. The first willow plantation 148 consisted of newly coppiced S. viminalis plants (first-year shoots) growing in an experimental 149 bioenergy plantations near the campus (Weih and Nordh 2005). The second plantation consisted 150 of more mature $S$. viminalis plants that had been left to grow for five years since the last coppice. 151 The two natural habitats consisted of mainly mature $S$. cinerea plants growing in a mixed conifer 152 forest, but also a few coppiced plants with re-sprouting shoots that had been cut back by a 153 harvester machine during the previous year to prevent the trees from interfering with traffic on a 154 nearby road. The four sites were chosen because they were easy to access and harbored similar 155 and moderate densities of $P$. vulgatissima. Female beetles were collected from plants by the hand 156 and beetles were brought to the laboratory and dissected under a microscope to confirm 157 reproductive status (Dalin 2011). Collections were made on July 15, July 22, July 29, August 7, 158 and the last collection was made on August 14 (Julian date: 226) when all (100\%) females were 159 found to be in diapause at all four study sites. The proportion of beetles in diapause was plotted 160 over time. Due to poor emergence of adult beetles at one of the natural sites, data from the two 161 natural habitats were pooled together in figure 1. 
163 From mid April to October (Julian dates 102-285) in 2010, we monitored the phenology and life-

164 cycle development of $P$. vulgatissima in one willow plantation ( $S$. viminalis) and one natural

165 willow habitat (S. cinerea) near Uppsala $\left(59^{\circ} 53^{\prime} \mathrm{N}, 17^{\circ} 38^{\prime} \mathrm{N}\right)$. The $S$. viminalis plantation

166 consisted of two-year old shoots (coppiced during the winter 2008/2009) whereas the natural

167 habitat consisted on mature (un-coppiced) S. cinerea plants. The two sites were visited at least

168 once, but most often twice, per week to estimate the number of adults, eggs and larvae of $P$.

169 vulgatissima on the plants in the two habitats. The number of individuals in different

170 developmental stages was counted during five-minute observation periods. One five-minute

171 period was devoted to search for adult beetles on the dorsal side of leaves. Another five-minute

172 period was devoted to search for eggs and larvae on the ventral side of leaves. The two sites were

173 visited on the same days and observations were mainly done during days with no precipitation

174 and minimal wind. The number of counted individuals in the different life-stages was plotted

175 over time.

176

177 Critical day-length response for diapause induction-genetic difference between populations or

178 phenotypic plasticity to host-plant quality?

179 The aim of this experiment was to: (1.) investigate if photoperiodic responses differ between $P$.

180 vulgatissima beetles originating from plantations and natural willow habitats, and (2.) study if

181 photoperiodic responses can be plastic in response to host-plant quality. From a previous study

182 we know that $P$. vulgatissima respond to photoperiod for the induction of diapause. The critical

183 day-length for the induction of diapause was estimated to be $18 \mathrm{hrs} 10 \mathrm{~min}$ when the beetles

184 were reared on greenhouse grown S. viminalis at $20^{\circ} \mathrm{C}$ in the laboratory (Dalin 2011). 
186 Life history theory predicts that univoltine populations should have a longer CDL than bivoltine

187 population at the same latitude and altitude (Roff 1980, Tauber et al. 1986). This is because

188 univoltine populations need to enter diapause earlier in the season, at a time-point when day-

189 lengths are longer, to avoid producing additional generations that may be unable to complete

190 development to the diapausing stage before the onset of winter. Consequently, based on the

191 observation that $P$. vulgatissima sometimes produce a second generation in plantations, we

192 predicted that CDL should be longer in univoltine populations from natural habitats than in

193 partially bivoltine populations from plantations.

194

195 An alternative hypothesis was that the induction of diapause can be influenced by host-plant

196 quality. This phenotypic plasticity hypothesis predicts that CDL can be modified by host-plant

197 quality. More specifically, we predicted that the propensity of diapause should increase when the

198 insects were reared on a sub-optimal host-plant. To test this hypothesis, we reared the insects on

199 two different willow species: S. viminalis which is frequently fed upon by $P$. vulgatissima in

200 plantations, and S. phylicifolia which is a native willow growing along creeks and rivers in

201 central Sweden but which is avoided by $P$. vulgatissima due to high concentrations of phenolic

202 glycosides in the leaves (Kendall et al. 1996).

203

204 Stem cuttings were collected in January 2010 from S. viminalis (clone 78021, used in Dalin

205 (2011)) growing in experimental plantations at the Ultuna campus, and from wild S. phylicifolia

206 growing along the river Fyrisån near the campus. Stem cutting were planted in individual pots

207 and placed in a greenhouse for shoot growth before the start of the experiment. When the plants

208 had started to produce foliage (in February), we collected overwintering beetles from two 
populations, one originating from a S. viminalis plantation $\left(59^{\circ} 56^{\prime} \mathrm{N}, 17^{\circ} 28^{\prime} \mathrm{E}\right)$, and one from a

210 natural S. cinerea stand located about $17 \mathrm{~km}$ east of the willow plantation. Beetles from the

211 willow plantation originated from the same population that was used in Dalin (2011). The two $P$.

212 vulgatissima populations were first reared for one generation under controlled conditions in a

213 greenhouse $\left(20: 4\right.$ L.D; $\left.15-20^{\circ} \mathrm{C}\right)$ to reduce potential influence of maternal effects on diapause

214 incidence. The two populations were then reared for another generation in the experiment (from

215 eggs to adults) on leaves of greenhouse grown S. viminalis and S. phylicifolia under controlled

216 conditions inside climate chambers (AB Ninolab, Upplands-Väsby, Sweden, Termaks Model

217 KB8400L). We used a similar experimental procedure as in Dalin (2011), including four climate

218 chambers with separate photoperiods (20:4, 19:5, 18:6 and 17:7 light:dark cycles) and constant

$21920^{\circ} \mathrm{C}$ temperature. In the climate chambers, we reared the beetles in groups of 50-100 larvae

220 inside transparent plastic containers $(19 \times 19 \times 11 \mathrm{~cm})$. We used two replicate containers per

221 photoperiod, host-plant and population treatments (16 containers in total). The containers were

222 sealed with a mesh net over the open top to provide ventilation. The number of emerging adult

223 beetles was counted every 2-3 days when fresh leaves were provided to ensure that larvae always

224 had a surplus of food. Pieces of wet oasis were placed at the base of leaf petioles to provide

225 moisture to the leaves. A layer of potting soil mixed with sand was added to the bottom of the

226 containers to be used as pupation substrate by larvae.

227

228 Emerging adult beetles were removed and kept in separate containers provided with fresh leaves

229 under the same experimental conditions as the beetles had been raised from eggs. The adults

230 were allowed to feed and mate for approximately 14 days. Female beetles were then dissected

231 under a microscope to confirm reproductive status (diapause or reproductively active). 
233 The propensity of diapause in P. vulgatissima was analyzed using logistic regression (PROC

234 GENMOD, binominal, logit; SAS Institute, 2008). Reproductive status (diapause or

235 reproductively active) of individual female beetles was the dependent, binary response variable

236 (1 for diapause, 0 for reproductively active). Thus, we pooled the results from the two replicate

237 containers and treated each female as an individual observation in the analyses (Dalin, 2011).

238 Photophase (hours of light), population origin and host-plant species were used as independent

239 categorical variables. Logistic regressions with inverse predictions (PROC PROBIT

240 INVERSECL, SAS Institute 2008) were used to calculate critical day-lengths ( $\pm 95 \%$ confidence

241 interval) (Dalin et al., 2010). Development time (i.e. the number of days it took for development

242 from eggs to adult eclosion) was compared among treatments using two-way ANOVA and

243 Tukey test for post-hoc treatment comparisons (PROC GLM, SAS Institute, 2008). The mean

244 number of days to adult eclosion was calculated for each replicate container to be used as

245 individual observations in the analysis.

247 Diapause incidence on coppiced versus mature willow plants

248 A second laboratory experiment was conducted in 2011 to further investigate the effect of host-

249 plant quality on diapause incidence in P. vulgatissima. The purpose of this experiment was to

250 test whether diapause in adult females is reduced when the beetles are reared on leaves from

251 previously coppiced and vigorously growing willow plants. For this experiment, we used a

252 mixture of beetles collected from willow plantations and natural willow habitats. The beetles

253 were exposed to three host-plant treatments: (1.) leaves from re-sprouting shoots of previously 
254 coppiced S. viminalis, (2.) leaves from re-sprouting shoots of experimentally coppiced $S$.

255 cinerea, and (3.) leaves from mature (un-coppiced) S. cinerea trees.

256

257 The beetles were collected in the field as eggs in May 2010. The proportion of eggs collected

258 from plantations and natural habitats was approximately 50:50. Larvae were reared to adulthood

259 under controlled conditions in a greenhouse to reduce maternal effects. Eggs from the second

260 generation were then distributed between nine $(3 \times 3)$ rearing containers (see above) inside a

261 climate chamber with constant 18.50 hours of light (photophase) and $20^{\circ} \mathrm{C}$. One container per

262 host-plant treatment was placed on three separate shelves (top, middle and bottom shelf) inside

263 the chamber. The groups of containers located on different shelves were treated as blocks in the

264 statistical analysis (described below). The specific photoperiod condition was chosen based on

265 the previous experiment indicating that diapause incidence will vary among individuals when

266 reared under this condition. Thus, we wanted to avoid all individuals becoming either

267 reproductively active or in diapause.

269 The beetles were fed fresh leaves collected from plants in the field every 2-3 days. The coppiced

270 plants used in the experiment had been coppiced (complete removal of shoots and branches) in

271 the previous year. The coppiced S. cinerea plants were located less than five meters away from

272 the mature $S$. cinerea to receive similar growth conditions of the two $S$. cinerea treatments. The

273 S. viminalis plants were growing in experimental plantations near the Ultuna campus (see

274 description of site above). Leaves collected in the field were immediately transported to the

275 laboratory and fed to larvae. We used similar methods described above for the rearing and testing

276 of reproductive status in female beetles. 
278 The propensity of diapause in relation to host-plant treatments was analyzed using logistic 279 regression (PROC GENMOD, binominal, logit; SAS Institute 2008). Reproductive status of 280 individual female beetles was again used as the dependent, binary response variable (1 for 281 diapause, 0 for reproductively active) and host-plant treatment and block the independent 282 categorical factors. We also scored the amount of fat-bodies in the abdomen of diapausing 283 females as either small or large amounts. Chi-square tests were used to compare fat-bodies 284 among host-plant treatments. In the analyses of fat-bodies, we pooled results from the three 285 blocks. The total number of females included in the analysis of fat-bodies was 15 for $S$.

286 viminalis, 50 for coppiced $S$. cinerea and 71 for mature $S$. cinerea. The size of adult females was 287 also estimated by measuring the width of the thorax using a scale in a microscope (9x 288 magnification lens). Data from 19-31 females per treatment were included in a one-way ANOVA 289 (PROC GLM; SAS Institute 2008) with host-plant treatment the independent factor.

\section{$291 \quad$ Results}

292 Life-cycle development and diapause induction of field populations

293 In the field, we found that first-generation adults of $P$. vulgatissima became reproductively active 294 if they enclosed from pupation before August in 2009 (before Julian date 205 in Fig. 1).

295 Although most beetles emerged later (around mid-August) and were in diapause, we observed 296 mating by first-generation adults in July on recently coppiced plants of both $S$. viminalis and $S$. 297 cinerea in the two habitats. However, the natural habitat mainly consisted of mature (un298 coppiced) S. cinerea plants on which we did not observe any mating. Overall, diapause induction 299 occurred earlier in the willow plantations with un-coppiced plants (five year-old shoots) and in 
300 the natural habitat (late July), whereas first-generation adults remained reproductively active at

301 least until early August in the recently coppiced S. viminalis plantation (Fig. 1).

302

303 In the subsequent year (2010), we did not find any differences in the phenology of adult

304 emergence from overwintering in the spring, or in the development of the first-generation broods

305 during the summer, or in the phenology of when first-generation adults enclosed from pupation,

306 between the willow plantation and the natural habitat studied (Fig. 2). However, we found that

307 first-generation adults produced a small partial second generation in the willow plantation by late

308 July-August in 2010 (Julian date 225-240), which was not observed in the natural habitat (Fig.

309 2).

310

311 Critical day-length responses for diapause induction-genetic difference between populations or

312 phenotypic plasticity to host-plant quality?

313 The laboratory experiment showed significant effects of photophase (hours of light) and host-

314 plant species on diapause incidence in $P$. vulgatissima (Table 1). Fig. 3 shows that the proportion

315 of females in diapause decreased with increasing day-length, and that a higher proportion of

316 females entered diapause on S. phylicifolia. Diapause incidence was also marginally affected by

317 population origin $(\mathrm{P}=0.049)$, with beetles originating from the natural willow habitat having a

318 higher diapause incidence than beetles from willow plantations. The non-significant Population $\mathrm{x}$

319 Photophase interaction suggests however that the two populations responded similarly to day-

320 length for the induction of diapause (Table 1). We found a significant Host-plant species $\mathrm{x}$

321 Photophase interaction, indicating different day-length responses of $P$. vulgatissima on the two

322 willow species (Table 1, Fig. 3). CDL was estimated to be 18.08 hours (95\% confidence interval: 
324 from willow plantation and natural willow habitat, respectively); and 18.77 hrs (18.53-19.03) or

32519.03 hrs (18.66-19.53) on S. phylicifolia.

326

327 Developmental time was significantly affected by day-length, but not by host-plant species or 328 population origin (Table 2). Fig. 4 shows a significant reduction in developmental time for 329 beetles reared under the shortest day-length treatment (17 hours of light).

Diapause incidence on coppiced versus mature willow plants

332 Diapause incidence in female $P$. vulgatissima was significantly affected by host-plant treatments $333\left(\chi^{2}=58.88\right.$, d.f. $=2, P<0.001$; Fig. 5). The proportion of females in diapause was $95 \pm 5 \%(n=$ 33475 ) on leaves from mature $S$. cinerea plants (means \pm standard errors calculated from three 335 replicate rearing containers), $60 \pm 11 \%(n=83)$ on coppiced $S$. cinerea, and $39 \pm 9 \%(n=72)$ on 336 coppiced S. viminalis. Diapause incidence was unaffected by the placement of containers within

337 the climate chamber, as shown be the non-significant block effect $\left(\chi^{2}=3.87\right.$, d.f. $\left.=2, P=0.15\right)$.

339 The amount of fat-bodies stored in the abdomen of diapausing females was higher in beetles

340 reared on the two coppiced treatments: coppiced $S$. viminalis vs. mature $S$. cinerea $\left(\chi^{2}=19.77\right.$,

$341 d . f .=1, P<0.001)$, coppiced vs. mature $S$. cinerea $\left(\chi^{2}=25.94, d . f .=1, P<0.001\right)$. No

342 difference was found between the two coppiced treatments of $S$. viminalis and $S$. cinerea $\left(\chi^{2}=\right.$

3431.60$, d.f. $=1, P>0.20)$. Host-plant treatments did not affect the size of adult females, as

344 measured by the width of the thorax $\left(F_{2,69}=0.69\right.$, d.f. $\left.=2, P=0.50\right)$. 


\section{Discussion}

347 The leaf beetle $P$. vulgatissima sometimes initiate a second generation in short-rotation coppiced

348 willow plantations in central Sweden. During 2010, we found that the beetles produced a partial

349 second generation in a S. viminalis plantation but not in a nearby natural $S$. cinerea habitat. This

350 second generation could not be explained by different phenology or development of first-

351 generation broods between the two habitats. However, the seasonal timing of diapause was found

352 to differ among leaf beetle populations in the field with diapause occurring 1-2 weeks later in

353 coppiced willow plantation than in mature (un-coppiced) willow stands. A postponed (later)

354 diapause induction could explain why the beetles sometimes initiate a second generation in 355 plantations.

357 Using climate chamber experiments, we did not detect any difference in the critical day-length

358 (CDL) response for diapause induction between beetles originating from plantations and natural

359 habitats. However, the propensity to enter diapause was significantly affected by host-plant

360 quality and was reduced when the beetles were reared on leaves from re-sprouting shoots of 361 previously coppiced willow plants than when reared on leaves from mature plants. Moreover,

362 diapause incidence was significantly reduced on the willow S. phylicifolia compared with $S$.

363 viminalis. The results suggest that host-plant quality influenced diapause induction in $P$.

364 vulgatissima. Willow plantations are coppiced for woody biomass every 3-4 years which

365 stimulates compensatory plant growth. The shoots of re-sprouting willows continue to elongate

366 and produce new leaves over the course of the season whereas mature plants cease leaf

367 production around mid-summer (Nakamura et al. 2005, P. Dalin pers. obs.). This implies that

368 coppiced willow may provide new leaves during an extended period of time, which may support 
369 the development of a second beetle generation. Although we lack information about the

370 performance of second-generation larvae, the results suggest that the current harvesting regime,

371 where willow plantations are coppiced every 3-4 years, can induce postponed diapause of $P$.

372 vulgatissima resulting in a second generation.

373

374 The fact that host-plant conditions can affect voltinism of herbivorous insects is not new and has

375 been documented in a number of insect species (Tauber et al. 1986, Hunter and McNeil 1997,

376 Wedell et al. 1997, Ishihara and Ohgushi 2006, Takagi and Miyashita 2008). However, host-

377 plant quality may influence insect voltinism both directly and indirectly (Wedell et al. 1997),

378 although few studies have been able to separate these effects experimentally. First, host-plant

379 quality can have a "trivial" indirect effect on insect voltinism in the field by affecting the timing

380 of when the insects reach the critical stage for diapause induction during development. In the

381 current study, we did not detect any difference in the development or seasonal occurrence of

382 naturally occurring leaf beetle populations between plantations and natural habitats, although the

383 beetles produced a second generation in the plantation. We therefore believe that we can reject

384 the "trivial-effect hypothesis" as an explanation to why the beetles sometimes produce a second

385 generation in plantations.

386

387 Larval host-plants may also affect the propensity of insects to enter diapause. This may either

388 occur as a direct response to cues from the host-plant or more indirectly via altered insect growth

389 (Wedell et al. 1997). Such plasticity in diapause threshold could prevent insects from producing

390 extra generations on a host-plant of poor or declining quality, a situation where their offspring

391 may fail to complete the extra generation. To our knowledge, no study has been able to confirm 
392 that insects respond directly to host-plant traits for the induction of diapause. This is because

393 diapause propensity often co-varies with insect development, such as growth rates, which also

394 may influence the choice of developmental pathway (Hunter and McNeil 1997, Wedell et al.

395 1997). Several studies show that insects are more likely to exhibit direct development (e.g.

396 produce another generation) when reared on host-plants that support rapid larval development

397 (Hunter and McNeil 1997, Wedell et al. 1997, Ishihara and Ohgushi 2006). This "growth-rate

398 hypothesis" predicts that insects can make use of their own growth rate as a cue to predict future

399 conditions and for choosing developmental pathways (Wedell et al. 1997). Feeding on a high

400 quality host-plant may, for example, indicate that the focal host-plant can support rapid

401 development not only in the present, but also in the future, which then may allow another

402 generation to develop within the same year.

403

404 We believe that our study reveals evidence that $P$. vulgatissima responded directly to cues

405 signaling host-plant quality for the induction of diapause. This was because we did not detect any

406 difference in developmental rate (time to adult eclosion) between beetles reared on S. viminalis

407 and S. phylicifolia in the laboratory experiment, although the beetles were more likely to enter

408 diapause on the latter plant species. The study is also one of the first to describe how the critical

409 photoperiodic response changes in response to host-plant conditions. We found that CDL was

410 prolonged by almost an hour when the beetles were reared on the willow S. phylicifolia. A

411 population CDL that is 19 hours or longer will certainly decrease the likelihood for a second

412 generation in central Sweden. Although these results in combination suggest that we can reject

413 the "growth-rate hypothesis" as an explanation for longer CDL on S. phylicifolia, it cannot be

414 ruled out that the insects may have responded to some other internal physiological process 
415 (rather than an external cue from the plant) when "choosing" developmental pathway in the

416 experiments. We found that adult beetles contained larger amounts of fat-bodies stored in the

417 abdomen when they had been reared on new leaves from vigorously growing willow plants than

418 when reared on old leaves from mature plants. This suggests that the beetles gained extra

419 resources when developing on new leaves. This is speculative, but if the beetles are unable to

420 gain enough resources during larval development, they may choose the developmental pathway

421 leading to diapause. However, until this is investigated more rigorously, we will reject the

422 original "growth-rate hypothesis" in its current form because the beetles would otherwise be

423 expected to develop faster on $S$. viminalis than on S. phylicifolia.

425 For insects that develop on the leaves of woody plants, the quality of their food often decline 426 over the course of the summer, which may reduce the growth and survival of individuals in

427 subsequent generations (Ishihara and Ohgushi 2006, Nylin et al. 2009). The leaves often

428 becomes tougher and accumulate higher concentrations of quantitative defense compounds after

429 expansion (Feeny 1970, Strong et al. 1994). Many herbivorous insects have therefore

430 synchronized egg hatch and the occurrence of young larval stages with the seasonal timing of

431 bud break to be able to feed on the tender new leaves in the spring that also often are more

432 nutritious than later in the season (Feeny 1970, van Asch and Visser 2007). In fact, many

433 herbivorous insect species feeding on woody plants are always univoltine with an obligatory

434 diapause that prevents them from producing additional generations (Tauber et al. 1986, Tammaru

435 et al. 2001). Although the leaf beetle $P$. vulgatissima has a facultative diapause, the species is

436 also normally univoltine in central Sweden (Dalin 2011). The first-generation completes

437 development to adulthood before mid August when day-degree models predict that they should 
438 be able to produce another generation in central Sweden (P. Dalin unpubl. data). Thus, is seems

439 that the seasonal climate could allow two generations in Sweden. As far as we know, the species

440 is univoltine at least down to central Europe where they may switch to a bivoltine life-cycle. One

441 possible reason why bivoltinism is restricted to central and southern Europe could be because the

442 quality of willow leaves declines over the course of the summer and, thus, can only support the

443 development of one generation per year further north. One may therefore wonder why the

444 species has a facultative diapause that can result in additional generations as far north as in

445 Sweden. Willow plants may, however, sometimes provide high-quality food also later in the

446 season that may allow a second generation. Willows are known to respond to disturbances, such

447 as wind breaks and mammalian herbivory, by producing many lateral shoots that grow

448 vigorously. These re-sprouting plants continue to produce new leaves throughout the summer

449 that may be of high-quality for leaf beetles also when a potential second generation is

450 developing.

451

452 In summary, the results reveal that the leaf beetle $P$. vulgatissima has a facultative diapause that

453 is influenced by both photoperiod and host-plant quality. We believe that this is the first study to

454 confirm that herbivorous insects can respond directly to host-plant quality for the induction of

455 diapause. This can allow the insects to produce extra insect generations under certain

456 circumstances, such as in response to a sudden but unpredictable availability of high-quality food

457 sources. It remains however to be investigated precisely what type of plant signal or cue the

458 insects respond to for the induction of diapause.

460 Acknowledgements 
461 The study was financed by a grant from the Carl Trygger Foundation to Peter Dalin and from the

462 Swedish Research Council to Sören Nylin, who also acknowledges support from the strategic

463 research programme EkoKlim at Stockholm University. The authors would like to thank Anders

464 Eriksson for technical support and Xiao-Ping Wang for suggestions on experimental design.

465

466 References

467 Altermatt, F. 2010. Climatic warming increases voltinism in European butterflies and moths. 468 Proc R Soc Lond (Biol) 277: 1281-1287.

469 Beck, S.D., 1980. Insect Photoperiodism. - Academic Press, New York.

470 Björkman, C. et al. 2000. Effects of leaf beetle damage on stem wood production in coppicing

$471 \quad$ willow. - Agric. For. Entomol. 2: 131-139.

472 Dalin, P. 2011. Diapause induction and termination in a commonly univoltine leaf beetle

473 (Phratora vulgatissima). - Insect Sci. 18, 443-450.

474 Dalin, P. et al. 2010. Seasonal adaptations to day length in ecotypes of Diorhabda spp.

475 (Coleoptera: Chrysomelidae) inform selection of agents against saltcedars (Tamarix

476 spp.). - Env. Entomol. 39: 1666-1675.

477 Dalin, P. et al. 2009. Reduced population control of an insect pest in managed willow

478 monocultures. - PLoS ONE 4(5): e5487.

479 Danks, H.V. 2007. The elements of seasonal adaptations in insects. - Canadian Entomologist

$480 \quad 139: 1-44$.

481 Dolezal, P. and Sehnal, F. 2007. Effects of photoperiod and temperature on the development and 482 diapause of the bark beetle Ips typographus. - J. Appl. Entomol. 131: 165-173. 
483 Feeny, P.1970. Seasonal changes in oak leaf tannins and nutrients as a cause of spring feeding by $484 \quad$ winter moth caterpillars. - Ecology 51: 565-581.

485 Gotthard, K. 2008. Adaptive growth decisions in butterflies. - BioScience 58: 222-230.

486 Gotthard, K. and Nylin, S. 1995. Adaptive plasticity and plasticity as an adaptation - a selective review of plastictity in animal morphology and life-history. - Oikos 74: 3-17.

488 Hunter, M.D. and McNeil, J.N. 1997. Host-plant quality influences diapause and voltinism in a polyphagous insect herbivore. - Ecology 78, 977-986.

Kostal, V. 2006. Eco-physiological phases of insect diapause. J. Insect Physiol. 52: 113-127.

Kurota, H. and Shimada, M. 2002. Geographical variation in the seasonal population dynamics

Ishihara, M. and Ohgushi, T. 2006. Reproductive inactivity and prolonged developmental time induced by seasonal decline in host plant quality in the willow leaf beetle Plagiodera versicolora (Coleoptera : Chrysomelidae). Env. Entomol. 35: 524-530.

Kendall, D.A. et al. 1996. Susceptibility of willow clones (Salix spp) to herbivory by Phyllodecta vulgatissima (L) and Galerucella lineola (Fab) (Coleoptera, Chrysomelidae). Ann. Appl. Biol. 129: 379-390. of Bruchidius dorsalis (Coleoptera : Bruchidae): constraints of temperature and host plant phenology. Env. Entomol. 31: 469-475.

Masaki, S. 1999. Seasonal adaptations of insects as revealed by latitudinal diapause clines. Entomological Science 2: 539-549.

Nakamura, M. et al. 2005. Flood initiates bottom-up cascades in a tri-trophic system: host plant regrowth increases densities of a leaf beetle and its predators. - J. Anim. Ecol. 74: 683691. 
Nelson, R.J. et al. 2010. Photoperiodism : the biological calendar. - Oxford University Press, New York; Oxford.

507 Nylin, S. and Gotthard, K. 1998. Plasticity in life-history traits. - Annu. Rev. Entomol. 43: 63-83.

508 Nylin, S. et al. 2009. Geographical variation in host plant utilization in the comma butterfly: the roles of time constraints and plant phenology. - Evolutionary Ecology 23: 807-825.

510 Poyry, J. et al. 2011. Climate-induced increase of moth multivoltinism in boreal regions. - Global Ecology and Biogeography 20: 289-298.

512 Roff, D. 1980. Optimizing development time in a seasonal environment: the 'ups and downs' of 513 clinal variation. - Oecologia 45: 202-208.

514 Sage, R.B. and Tucker, K. 1998. The distribution of Phratora vulgatissima (Coleoptera :

515 Chrysomelidae) on cultivated willows in Britain and Ireland. - Eur. J. Forest Pathol. 28: $516 \quad 289-296$.

517 SAS Institute. 2008. SAS/STAT User's guide, version 9.1. - SAS Institute, Cary, NC.

518 Saunders, D.S. 2010. Photoperiodism in insects: migration and diapause responses. - In: Nelson, R.J.et al. (eds.), Photoperiodism: the biological calendar. Oxford University Press, New York, pp. 218-257.

Solbreck, C. and Sillen-Tullberg, B. 1981. Control of diapause in a monovoltine insect, Lygaeus equestris (Heteroptera). - Oikos 36: 68-74.

Steinbauer, M.J. et al. 2004. Modelling a forest lepidopteran: phenological plasticity determines voltinism which influences population dynamics. - Forest Ecol. Manag. 198: 117-131.

525 Strong, D.R. et al.1994. Insects on plants. - Blackwell Publishing, Oxford, U.K.

526 Takagi, S. and Miyashita, T. 2008. Host plant quality influences diapause induction of Byasa 527 alcinous (Lepidoptera : Papilionidae). - Ann. Entomol. Soc. Am. 101: 392-396. 
528 Tammaru, T. et al. 2001. Autumnal moth - why autumnal? - Ecol. Entomol. 26: 646-654.

529 Tauber, M.J. et al.1986. Seasonal adaptations of insects. - Oxford University Press, New York.

530 Tobin, P.C. et al. 2008. Historical and projected interactions between climate change and insect

$531 \quad$ voltinism in a multivoltine species. - Global Change Biol. 14: 951-957.

532 van Asch, M. and Visser, M.E. 2007. Phenology of forest caterpillars and their host trees: the

533 importance of synchrony. Ann. Rev. Entomol. 52: 37-55.

534 Wedell, N. et al. 1997. Effects of larval host plant and sex on the propensity to enter diapause in 535 the comma butterfly. - Oikos 78: 569-575.

536 Weih, M. and Nordh, N.E. 2005. Determinants of biomass production in hybrid willows and 537 prediction of field performance from pot studies. - Tree Physiology 25: 1197-1206.

538 Yamanaka, T. et al. 2008. Adaptation to the new land or effect of global warming? An age539 structured model for rapid voltinism change in an alien lepidopteran pest. J. Anim. Ecol. $540 \quad 77: 585-596$. 
543 Table 1. Results of logistic regression (binominal, logit, type 3) investigating the effects of host544 plant species, population origin and hours of light (photophase) on diapause incidence in two 545 populations of Phratora vulgatissima originating from willow plantations and natural willow 546 habitats in central Sweden (59 $56^{\prime} \mathrm{N}$ latitude).

\begin{tabular}{lccc}
\hline Effect & $\chi^{2}$ & $d . f$. & $P$ \\
\hline Host-plant species (Host) & 35.1 & 1 & $<0.001$ \\
Population origin (Pop) & 3.9 & 1 & 0.049 \\
Hours of light (Photophase) & 425.2 & 3 & $<0.001$ \\
Host x Photophase & 31.2 & 3 & $<0.001$ \\
Pop x Photophase & 3.2 & 3 & 0.359 \\
Host x Pop & 0.4 & 1 & 0.511 \\
\hline
\end{tabular}


549 Table 2. Results of ANOVA investigating the effects of host-plant species, population origin and 550 hours of light (photophase) on development time (days) from eggs to adult in two populations of 551 Phratora vulgatissima origination from willow plantations and natural willow habitat in central 552 Sweden $\left(59^{\circ} 56^{\prime} \mathrm{N}\right.$ latitude).

\begin{tabular}{lcccc}
\hline Effect & $M S$ & $d . f$. & $F$ & $P$ \\
\hline Host-plant species (Host) & 0.1 & 1 & 0.2 & 0.699 \\
Population origin (Pop) & 1.1 & 1 & 1.4 & 0.255 \\
Hours of light (Photophase) & 37.7 & 3 & 46.2 & $<0.001$ \\
Host x Photophase. & 0.2 & 3 & 0.2 & 0.926 \\
Pop x Photophase & 0.5 & 3 & 0.6 & 0.647 \\
Host x Pop & 0.5 & 1 & 0.6 & 0.443 \\
\hline
\end{tabular}


554 Fig. 1. Field diapause induction of first-generation adult females of Phratora vulgatissima on $S$. 555 cinerea in natural habitats and on S. viminalis in willow plantations in 2009.

$\longrightarrow$ Willow plantation (Salix viminalis, mature 5 year shoots) Natural willows (Salix cinerea)

$-\nabla-$ Willow plantation (S. viminalis, coppiced 1st year shoots)

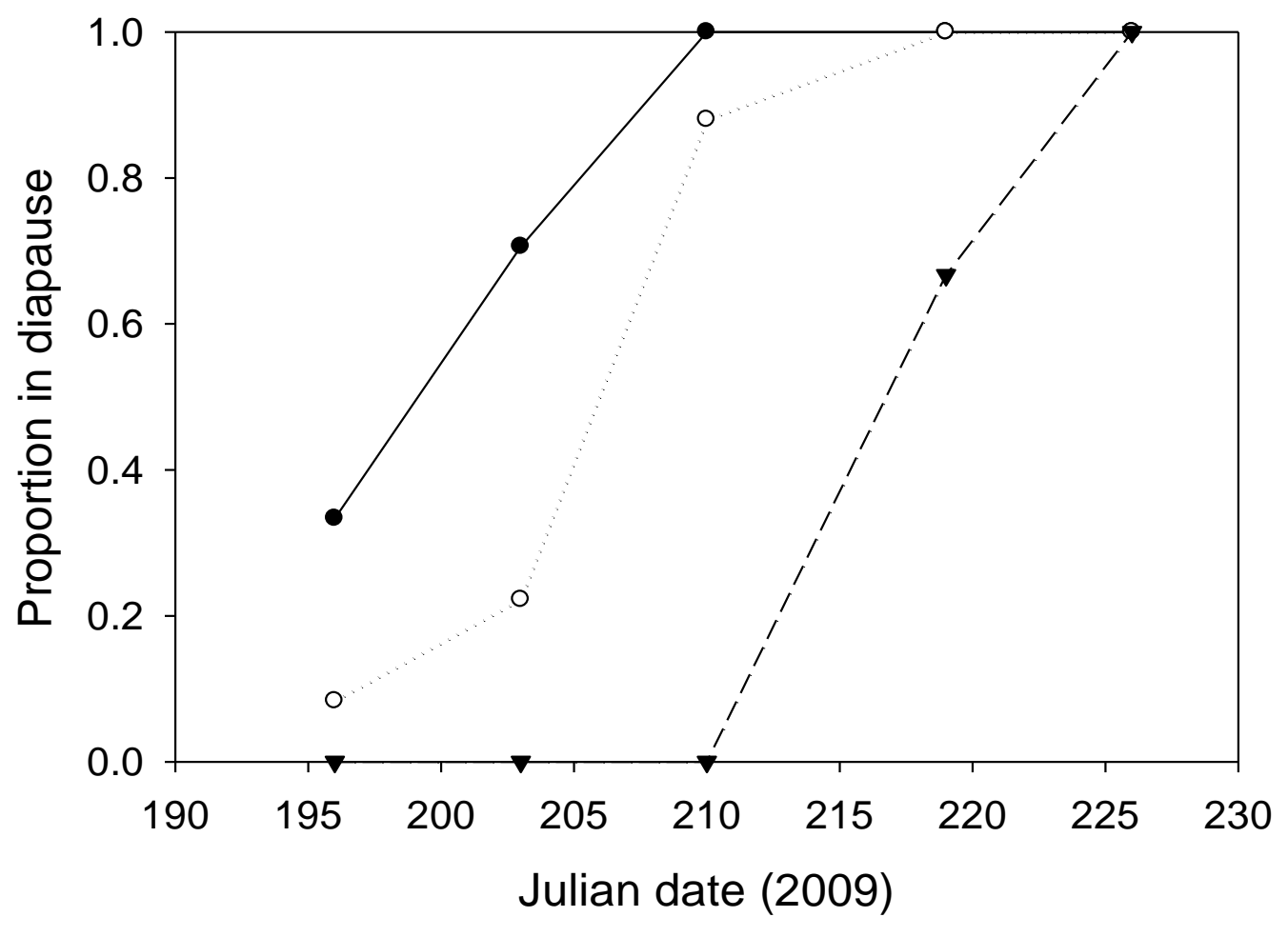


558 Fig. 2. Phenology and life-cycle development of the leaf beetle Phratora vulgatissima in a 559 willow plantation (Salix viminalis) and a natural willow habitat (S. cinerea) during 2010. The 560 beetles produced a partial second generation in the plantation (Julian dates 225-240).

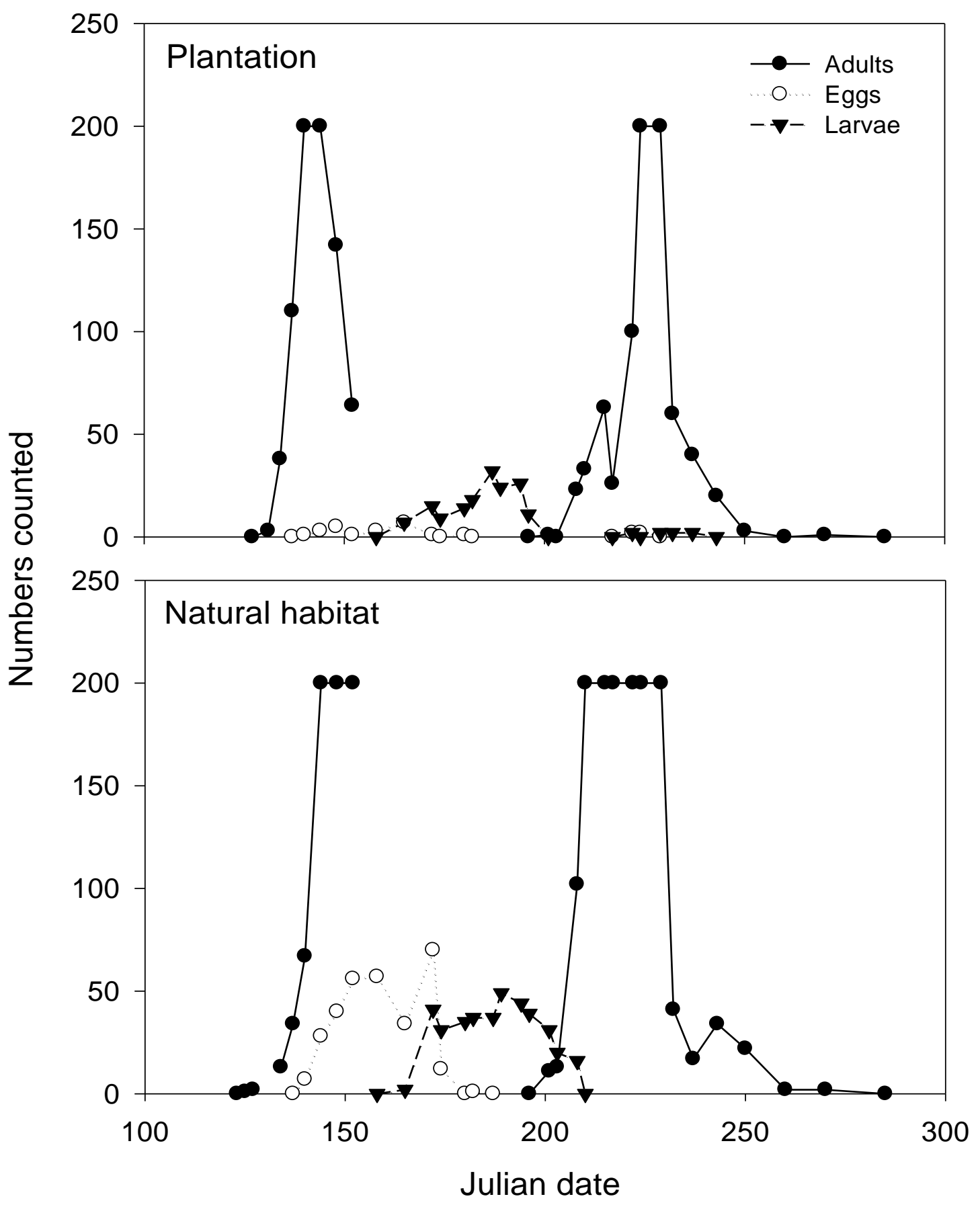


563 Fig. 3. Diapause incidence of two populations of Phratora vulgatissima originating from the 564 same latitude $\left(59^{\circ} 56^{\prime} \mathrm{N}\right)$, reared on greenhouse-grown plants of Salix viminalis (circles) and $S$. 565 phylicifolia (triangles), under four day-length (hours of light) treatments and constant $20^{\circ} \mathrm{C}$. Pop. 566 A (filled symbols) represent beetles originating from a willow plantation ( $S$. viminalis), whereas 567 Pop. B (open symbols) represents beetles from a natural willow habitat (S. cinerea).
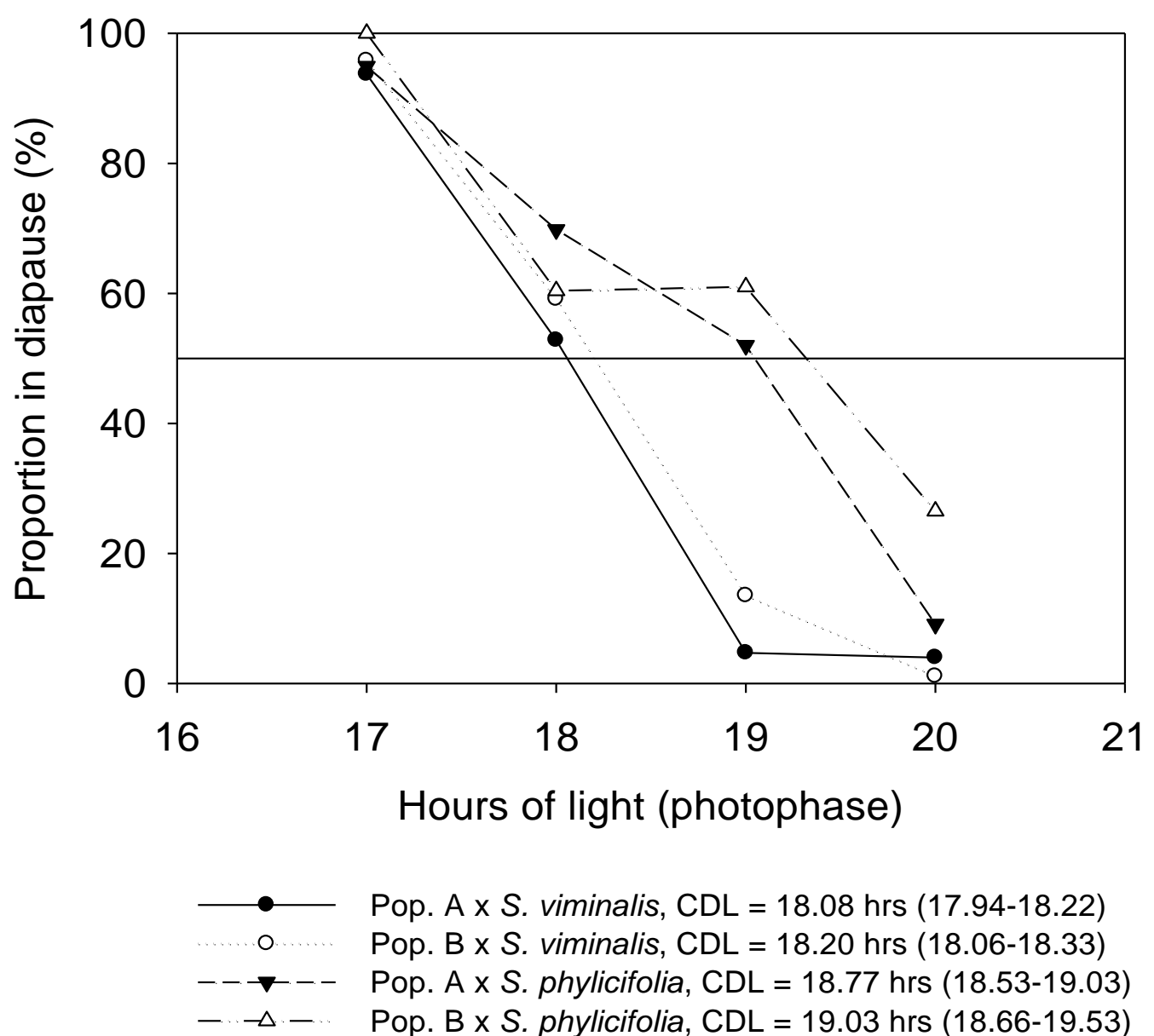

Pop. A x S. viminalis, CDL $=18.08$ hrs (17.94-18.22) Pop. B x S. viminalis, CDL $=18.20$ hrs (18.06-18.33)

$-\cdots-\cdots$ Pop. A $\times$ S. phylicifolia, CDL $=18.77$ hrs $(18.53-19.03)$

Pop. B X S. phylicifolia, CDL $=19.03$ hrs $(18.66-19.53)$

$50 \%$ reference line 
570 Fig. 4. Developmental time from egg to adult of Phratora vulgatissima in relation to day-length 571 (hours of light) when reared on Salix viminalis and S. phylicifolia at $20^{\circ} \mathrm{C}$. Different superscripts 572 represent significant different means among day-length treatments, as revealed by Tukey tests.

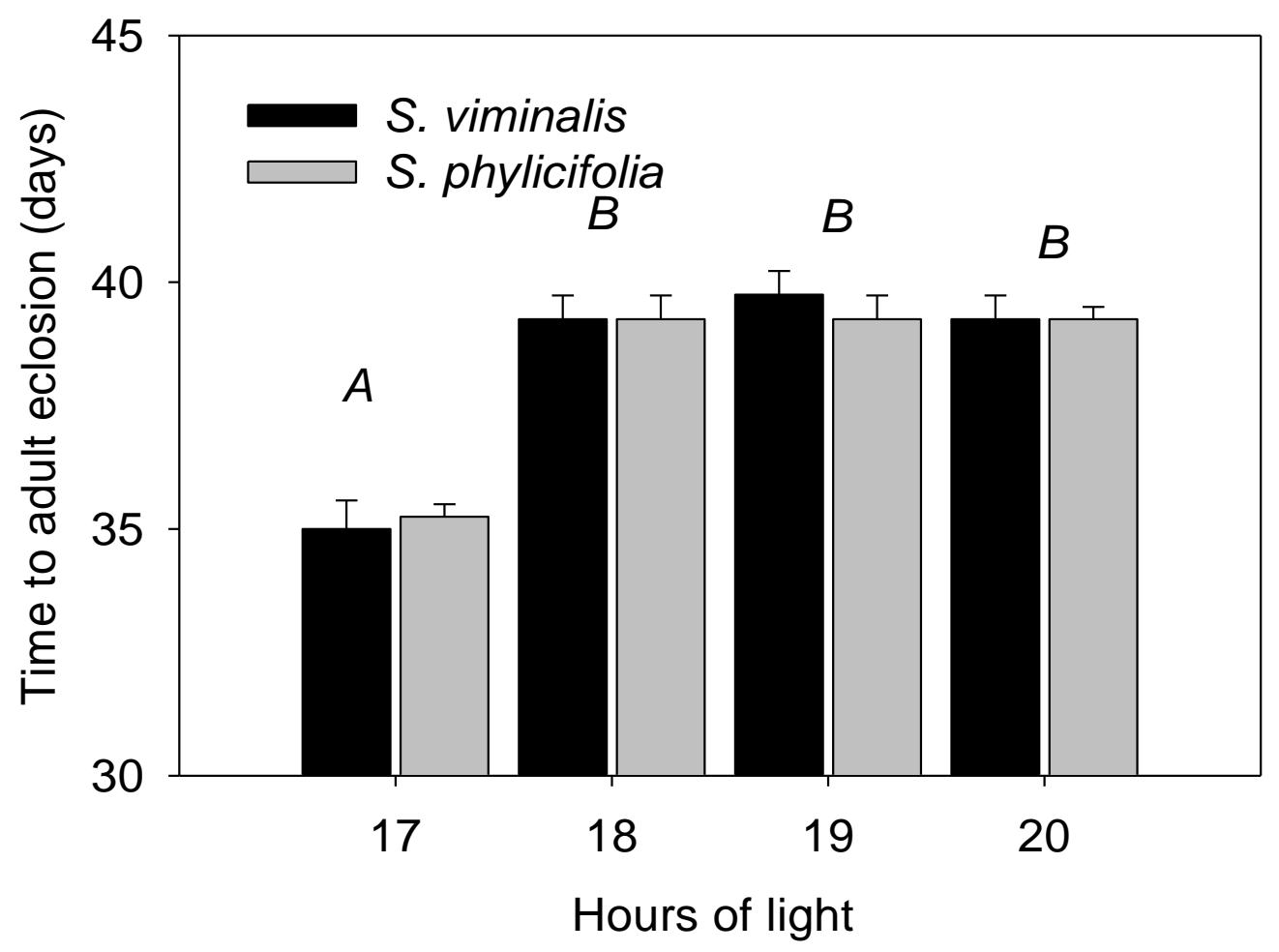

573 
574 Fig. 5. Diapause incidence of Phratora vulgatissima when reared on leaves from three host-plant 575 treatments: previously coppiced Salix viminalis, previously coppiced S. cinerea, and mature (un576 coppiced) S. cinerea trees in the field. The figure presents the results from three replicate rearing 577 containers per treatment with groups of larvae reared under controlled conditions (18.5 hours of 578 light, $20^{\circ} \mathrm{C}$ ) in a climate chamber.

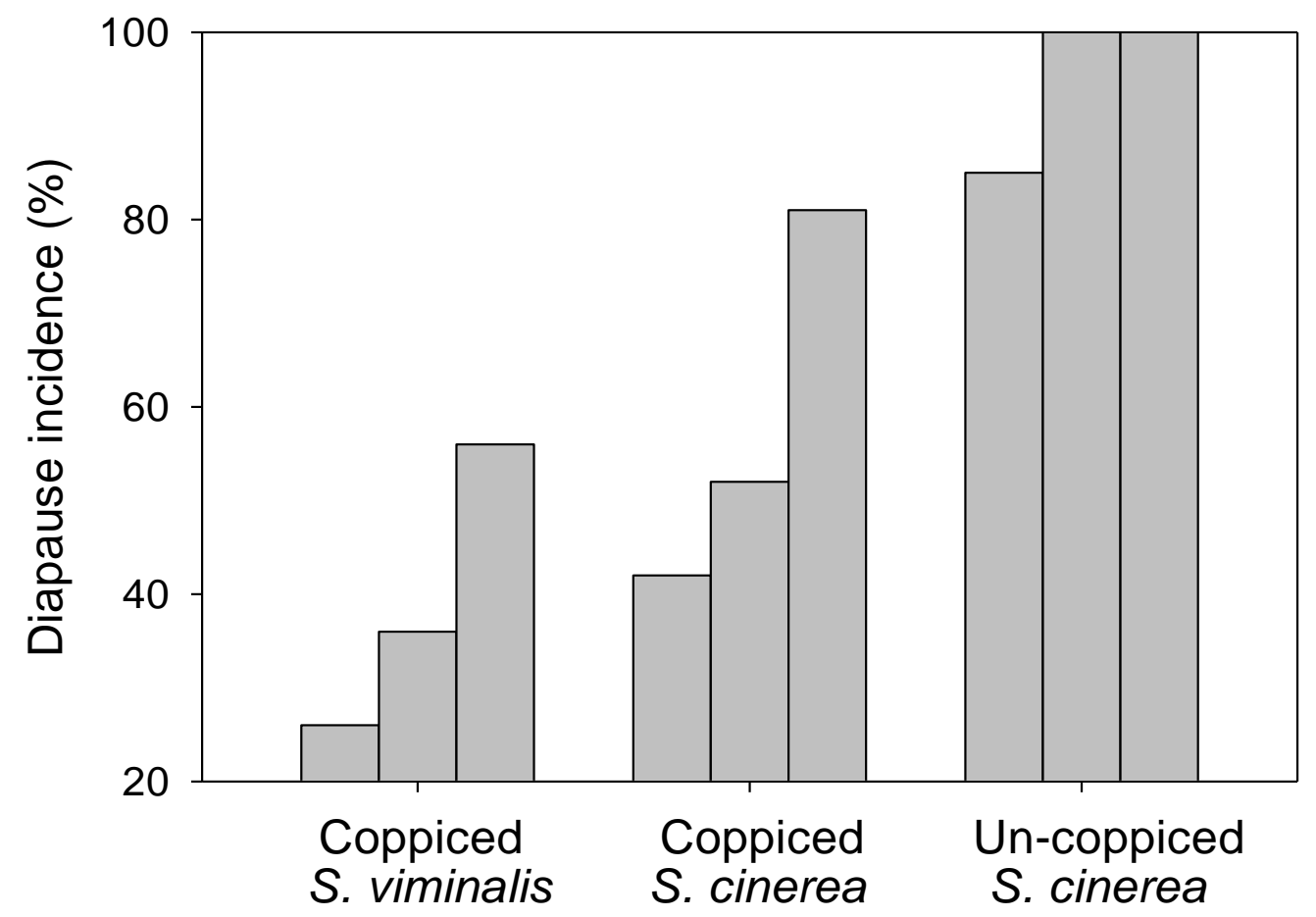

